\title{
Diffuse Infiltrative Lymphocytosis Syndrome: A Case With Multiple Extra-Glandular Infiltrations
}

\author{
Ana-Maria Copaescu ${ }^{\mathrm{a}, \mathrm{b}}$, Jean-Pascal Costa ${ }^{\mathrm{a}}$
}

\begin{abstract}
Diffuse infiltrative lymphocytosis syndrome (DILS) is a rare condition characterized by circulating and infiltrating CD8 T lymphocytes and described mostly in patients infected with the human immunodeficiency virus (HIV). As it has an impact on several organs in the human body and thus mimics different initial clinical presentations, proper recognition is essential. This report describes a case of DILS with renal, pulmonary and nervous system infiltrates. The patient's clinical presentation and response to treatment are properly described in order to portray a clear picture of this condition. The DILS definition, diagnostic and management are reviewed based on a thorough literature review. Also, a differential diagnosis is resumed for each specific organ infiltrate. In cases of severe renal failure, clinicians must consider the DILS diagnostic in order to initiate proper treatment.
\end{abstract}

Keywords: Diffuse infiltrative lymphocytosis syndrome; Human immunodeficiency virus; Acquired immune deficiency syndrome; Interstitial nephritis; Lymphocytic pneumonitis

\section{Introduction}

Renal failure is a common condition with numerous causes and degrees of severity. Lack of understanding of some of the rare causes of renal failure could delay proper diagnosis and treatment.

Diffuse infiltrative lymphocytosis syndrome (DILS), first defined 25 years ago [1], is a rare condition whose prevalence remains scantily described in the literature. Mostly observed in patients with human immunodeficiency virus (HIV), this disorder is characterized by circulating $\mathrm{CD}^{+} \mathrm{T}$-cell lymphocytosis, salivary gland enlargement or xerostomia [2] and visceral infiltration.

Manuscript accepted for publication June 17, 2016

aDivision of Internal Medicine, Centre Hospitalier de l'Universite de Montreal (CHUM), Montreal, Canada

${ }^{b}$ Corresponding Author: Ana-Maria Copaescu, Division of Internal Medicine, Centre Hospitalier de l'Universite de Montreal (CHUM), 1560 Sherbrooke Street East, H2L 4M1, Montreal, Canada. Email: ana.copaescu@gmail.com

doi: http://dx.doi.org/10.14740/jmc2558w
In this report, we describe a case of DILS with renal, pulmonary and possible nervous system infiltrates in an HIV patient, AIDS stage. A discussion and a literature review follow.

\section{Case Report}

A 48-year-old African American patient presented to our institution for dry and itching skin. The patient, originally from the Republic of Benin, had moved to Canada 2 years before this event. He got divorced before leaving his country of origin and denied other sexual contacts as well as prior sexual relationships with men. The questionnaire was negative except for diffuse skin itching. The patient denied Sjogren like symptoms, such as xerophtalmia or xerostomia.

At the initial evaluation, he presented an asymptomatic systolic hypertension at around 180. As for the physical examination, he had a $2 \times 3 \mathrm{~cm}$ neck adenopathy as well as a diffusely lichenified skin, with several papular scaly lesions, particularly observed on the lower extremities and on the back, compatible with ichthyosis. No other findings were reported in the physical examination. His electrocardiogram showed a mild left ventricular hypertrophy.

The hemoglobin and platelets levels were low $(57 \mathrm{~g} / \mathrm{L}$ and $74 \times 10^{9} / \mathrm{L}$, respectively) and blood smear contained schistocytes. A hemolytic-uremic syndrome was suspected and he was referred for plasmapheresis. A protein electrophoresis and a bone marrow biopsy were unremarkable.

The creatinine level was $1,030 \mu \mathrm{mol} / \mathrm{L}(11.705 \mathrm{mg} / \mathrm{dL})$ and he was referred to the nephrology department for dialysis. A renal needle biopsy excluded a possible glomerular lesion and other less likely pathologies, but confirmed an acute interstitial nephritis (AIN). The moderate to important uninucleated interstitial infiltrate was marked with 50\% CD8 cytotoxic lymphocytes (immunohistochemical coloration) (Fig. 1). The findings for the direct immunofluorescence were non-specific. Also, vascular lesions probably due to hypertension were observed.

The blood work was negative for hepatitis A, B, C viruses, parvovirus B19, Epstein-Barr virus, cytomegalovirus, respiratory syncytial virus, JC/BK virus, Streptococcus pneumonia, Mycobacterium tuberculosis, Treponema pallidum (syphilis), cryptococcus, Toxoplasma gondii and plasmodium (malaria). An ENA panel was non-conclusive. The test for cytoplasmicantineutrophil cytoplasmic antibodies (c-ANCA), used for granulomatosis with polyangiitis, which can also be positive in HIV and tuberculosis patients, was positive $(>8)$. 

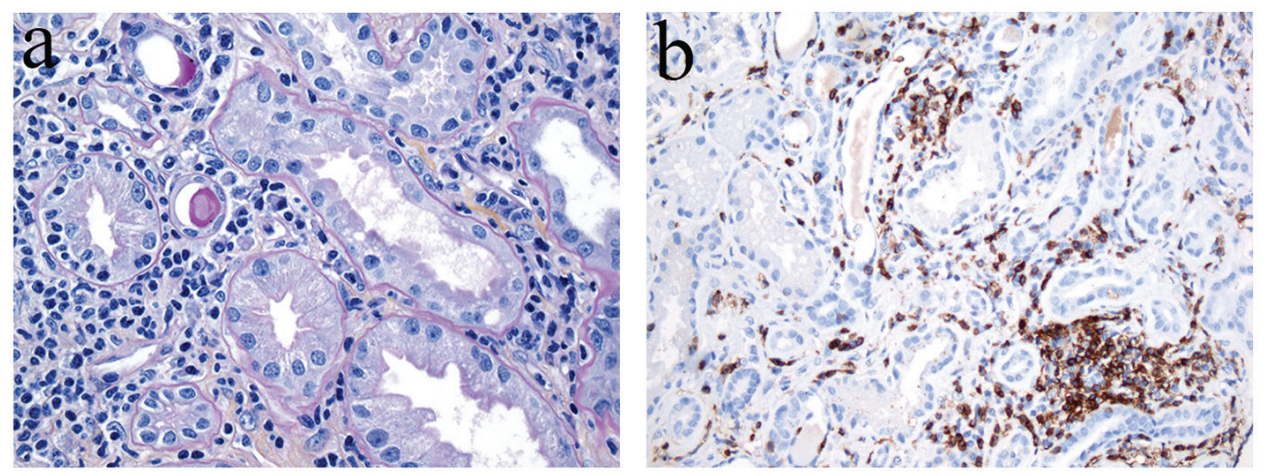

Figure 1. Renal biopsy specimen - renal interstitium infiltrated with large inflammatory cell aggregates containing lymphocytes, plasmocytes and fibrosis. (a) The lymphocytic and plasmocytic interstitial tubulitis is associated with segmental and global glomerulosclerosis. (b) The lymphoid cells express CD8 ${ }^{+}$and $\mathrm{CD} 138^{+}$(immunostain). Few CD4 ${ }^{+}$lymphocytes were present (not shown). Original magnification of each panel, $\times 400$.

The pulmonary X-ray showed a diffuse interstitial infiltrate and prominent hilar blood vessels. A chest CT scan indicated several cystic lesions and multiple non-specific groundglass pulmonary opacities localized mostly in the inferior lobes (Fig. 2a, b). The differential diagnosis included Pneumocystis jirovecii pneumonia (PJP), tuberculosis, diffuse alveolar hemorrhage (DAH) syndrome, lymphoproliferative syndrome, histiocytosis and lymphocytic interstitial pneumonia. Tuberculosis was excluded. A bronchoscopy was performed and a capillaritis was excluded. The bronchoalveolar lavage confirmed a 94\% CD8 cytotoxic lymphocytes infiltrate and a CD4/CD8 ratio of 0.02 . The secretions sent for culture were negative for virus, bacteria and fungus (PJP, Aspergillus).

The neck mass was also addressed. A neck CT scan was not found in favor of a lymphoproliferative syndrome and thus a biopsy was not judged necessary.

Investigations such as a skeletal survey, an abdominal ultrasound and CT scan remained non-conclusive.

During his hospital stay, a minor paresis of his left upper extremity was noted. A brain CT scan excluded a hemorrhagic or ischemic event but a diffuse hypodensity of the white matter (leukopathy) and a discrete outgrowth of the subarachnoid spaces were observed.

Ultimately, the HIV test was confirmed positive with a
CD4 count of 60 cells $/ \mathrm{mm}^{3}$, a CD8 of 340 cells $/ \mathrm{mm}^{3}$ and a $\mathrm{CD} 4 / \mathrm{CD} 8$ ratio of 0.17 .

The diagnostic of DILS was considered. The human leukocyte antigen (HLA)-DR5/6/7 test was negative.

A highly active antiretroviral therapy (HAART) adjusted for renal impairment was started. A literature review highlighted the positive effect of a high dose prednisone treatment on the renal function. The patient was started on $50 \mathrm{mg}$ of prednisone for 2 weeks, followed by gradual tapering. He also received dialysis treatment three times a week.

At 1-year follow-up, the patient's renal function improved with a creatinine level at $320 \mu \mathrm{mol} / \mathrm{L}(4.284 \mathrm{mg} / \mathrm{dL})$ and a hemoglobin value at $116 \mathrm{~g} / \mathrm{L}$. The $\mathrm{CD} 4 / \mathrm{CD} 8$ ratio increased at $0.32, \mathrm{CD} 4$ level at 220 and CD8 at 710 .

\section{Discussion}

\section{DILS}

The first definition of the DILS, which matches the current one available in the literature, was first formulated in 1989 by Itescu et al [1]. In that period, the percentage of HIV patients
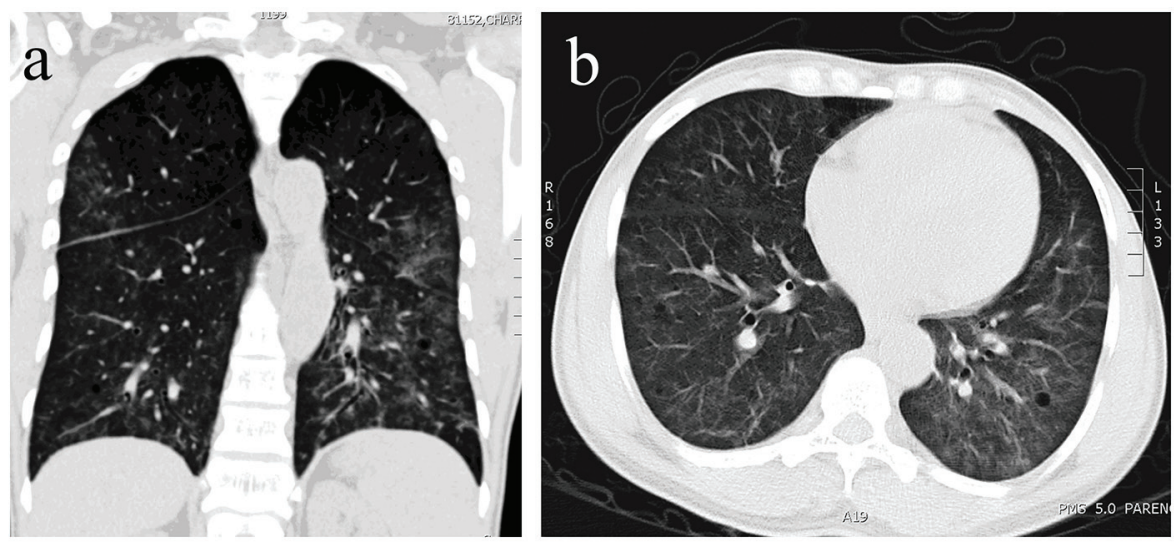

Figure 2. (a, b) Small patchy areas of alveolar consolidation. 
diagnosed with DILS was around 3-4\% [3] with a higher prevalence observed in the African American population $[3,4]$. According to several authors [5-9], DILS should be excluded in the absence of glandular involvement. Thus, there is a possibility that some DILS cases are overlooked in the absence of the sicca symptoms and/or the parotid enlargement. Our patient presented with important extra-glandular $\mathrm{CD}^{+} \mathrm{T}$ lymphocytes infiltration which made DILS possible even if it did not match the proposed definition. Therefore, it could be reasonable to recommend a histological rather than a clinical diagnostic for the DILS. Nevertheless, Maganti et al [2] indicated that the biopsy investigation in patients taking HAART could be normal and thus proposed the use of a gallium scintigraphy. Kazi et al [4] also recommended this diagnostic method, the possible tracer uptake in the salivary glands eliminating the need for an invasive gland biopsy. Finally, DILS was also described in a patient not infected with HIV [10]. Thus, it could be argued that the definition should include non-HIV-infected patients.

Interestingly, the extra-glandular features are frequently described in patients that are not on antiretroviral therapy [2], like our case. Thus, with the arrival of HAART, the number of cases described diminished, which suggests a viral driven response [2]. If we take into account the viral antigen theory [11], the HIV would be causing an immune response in our patients. The HIV mainly destroys $\mathrm{CD} 4^{+} \mathrm{T}$ helper lymphocytes and thus induces progressive immunity impairment and increases the susceptibility to opportunistic infections. In DILS, the human stem cells could recognize the HIV and induce a release of a high number of lymphocytes; in this case, CD8 T cells. Also, it is suggested that these cells have the same memory phenotype whether they are found in the blood stream or in the tissues [12].

Finally, it was suggested that a type of neoplastic proliferation of lymphocytes could explain the increased number of CD8 T cells. This hypothesis was rejected by Itescu et al who summarized the histological findings of $10 \mathrm{HIV}$ patients with DILS [12]. Our patient's renal biopsy supports the same findings seeing the lack of glomerular involvement and the preserved parenchymal structures.

In a study regrouping $523 \mathrm{HIV}$ patients [3], those with DILS had less advanced clinical disease. A study from 1993 [12] analyzed the data of 26 individuals with DILS and determined that the annual rate of developing an opportunistic infection was $0.9 \%$. The main hypothesis for this protective mechanism could be that the lymphocyte infiltration might have a role in suppressing the HIV replication in the infected cells [12]. Another study speculates that some HIV patients, mostly of African descent, when lacking sufficient CD4 T lymphocytes and in response to different infections, could express an overproduction of CD8 cells in response to endotoxins [13].

\section{Renal infiltration}

In individuals infected with HIV, $30 \%$ of the acute kidney injuries are caused by AIN [14]. The first cause of AIN is drug related. In our case, the patient was not taking any medication prior to his hospital stay. Frequently reported medications are antiretroviral drugs, antibiotics, proton pump inhibitors,
NSAIDs and allopurinol [15]. Other possible causes include infections (pyelonephritis and mycobacterial infection), systemic diseases (such as malignancy) and, more specifically in HIV individuals, the immune reconstitution inflammatory syndrome (IRIS) and the DILS [16]. This differential diagnosis should be considered in HIV patients with renal impairment. In the IRIS, the systemic infiltration is composed mostly of CD4 type cells. Also, the IRIS is typically related to an HAARTinduced immune activation and our patient was not on this treatment at the time of the diagnosis.

The kidney injury is not very frequent in DILS patients, being described in approximately $10 \%$ of cases [13]. The renal infiltration was observed in patients without ongoing HAART, but some case reports $[9,17]$ describe this syndrome in treated HIV patients.

As for the renal biopsy of our patient, the lack of glomerular disease excluded a possible HIV-associated nephropathy or HIV-related immune complex disease [18].

\section{Pulmonary interstitial infiltrate}

Pulmonary pathologies in HIV patients can be explained by a large number of etiologies, most important ones (97\%) being infectious [19]. Our patient did not show any clinical or laboratory infectious signs. More importantly, a bronchoscopy allowed us to exclude Pneumocystis jirovecii, aerobic and anaerobic bacteria, fungi, mycobacteria and viruses as suggested by the 21st century update on HIV pulmonary infections [19].

Ironically, according to a study from 1994 [20], lymphoid interstitial pneumonia was first portrayed in 1966 and, as we know, HIV was not described at that time. The characterization of this condition is remarkably similar to the DILS described with the Sjogren syndrome, immune dysregulation and CD8 lymphocytes in significantly greater number than CD4 lymphocytes. A shared pathophysiology of these conditions is questionable. However, this type of pneumonia was associated with a progression to Kaposi sarcoma [20], which is not the case for DILS. The concept of lymphoid interstitial pneumonia is now recognized and classified in the category of nonspecific cellular interstitial pneumonias but a DILS association is not mentioned. A chest radiography classification was suggested by Saldana (1994) [20], with four grades: 0 (normal), I (reticular infiltrates with nodules), II (grade I and areas of alveolar consolidation) and III (areas of alveolar consolidation and little or absent interstitial component).

Although pneumonitis seems to be the most redoubtable complication of DILS [4], few case reports describe these pulmonary infiltrates.

\section{Central Nervous System (CNS) and Peripheral Nervous System (PNS) infiltrate}

In the HIV with low CD4 levels, the spectrum of CNS diseases is large and, in this case, the opportunistic infections such as toxoplasmosis and cryptococcus were excluded. Seeing the description of the brain CT scan mentioned above, we hypoth- 
esized the diffuse white matter hypodensity could be a CD 8 lymphocyte infiltration. A study from 2004 [21] describes brain autopsies from patients with DILS as diffuse infiltration of the white matter, leptomeninges and gray matter by macrophages and $\mathrm{CD}^{+} / \mathrm{CD}^{+} / \mathrm{CD}^{+} / \mathrm{CD} 4-$ lymphocytes. Unfortunately, immunophenotyping of the lymphocytes was not performed but, normally, $\mathrm{CD} 8^{+}$cells are found only in a small proportion in the CNS.

As mentioned, our patient's neurological examination revealed a small upper left side paresis that could have been of central or peripheral origin. An electromyography study could have helped us differentiate further.

A peripheral neuropathy can be caused by a $\mathrm{CD} 8^{+}$lymphocyte infiltration. The few cases underlined compromises position and vibration sense, decreased reflexes and a painful paresthesia, usually in the lower extremities and in a symmetrical pattern $[22,23]$. The nerve biopsy in the DILS shows axon loss and a $\mathrm{CD} 8^{+}$cell infiltration of the epineurial and endoneurial vessels [22]. The main hypothesis is that the nerve lesions are caused by the discharge of CD8 T cell's inflammatory cytokines.

Another differential diagnostic must also be addressed. Indeed, in the setting of peripheral neuropathy, a muscle infiltration can also be found making the clinical diagnostic more challenging. A more recent article by Meybeck et al, underlines that HIV-associated polymyositis can be a part of the DILS spectrum $[23,24]$.

As mentioned, several organs were most probably infiltrated in this patient's case. Other visceral infiltrates described in the literature include sinonasal [24], breast, intestine and liver infiltrates [12].

\section{Treatment}

The rarity of DILS cases explains the lack of studies describing treatment options. The general agreement between different authors is that the primary treatment line should be antiretroviral therapy.

Specifically, for the renal condition, several case reports $[9,13,17,18]$ suggest the use of corticosteroid therapy. As mentioned, our patient was started on prednisone combined with regular renal dialysis. In these cases, when the kidney damage is severe, one should not underestimate the importance of renal protective measures such as blood pressure control, dyslipidemia treatment, diabetes management, smoking cessation and avoidance of nephrotoxic products [18]. Finally, the choice of antiretroviral therapy is also influenced by the renal function.

As for the symptomatic pulmonary infiltration, some authors [2] recommend the use of $60 \mathrm{mg} /$ day of prednisone.

\section{Conclusion}

In the clinical environment, an HIV diagnosed patient could represent a challenge for the eager internist. Despite the enormous progress accomplished in this field, there is still a lack of understanding of HIV-associated pathologies such as the DILS.

The various initial clinical presentations of our multi-ethnical patients diagnosed with HIV enlighten us on the importance of keeping up to date with pathologies such as DILS that should have a special place in our clinical evaluation as the treatment options could be viewed differently. Finally, clinicians unaware of the clinical manifestations of this condition may fail to initiate proper therapy.

\section{Acknowledgments}

The authors would like to underline the contribution of the following medical departments from the Notre-Dame Hospital, CHUM: the Internal Medicine Department, the Microbiology and Infectious Disease Department, the Nephrology and Dialysis Department, the Neurology Department, and the Pathology Department and Radiology Department. Their contribution made the diagnostic and treatment possible for our patient.

\section{Grant Support}

None.

\section{Conflicts of Interest}

None.

\section{References}

1. Itescu S, Brancato LJ, Winchester R. A sicca syndrome in HIV infection: association with HLA-DR5 and CD8 lymphocytosis. Lancet. 1989;2(8661):466-468.

2. Maganti RM, Reveille JD, Williams FM. Therapy insight: the changing spectrum of rheumatic disease in HIV infection. Nat Clin Pract Rheumatol. 2008;4(8):428-438.

3. Williams FM, Cohen PR, Jumshyd J, Reveille JD. Prevalence of the diffuse infiltrative lymphocytosis syndrome among human immunodeficiency virus type 1-positive outpatients. Arthritis Rheum. 1998;41(5):863-868.

4. Kazi S, Cohen PR, Williams F, Schempp R, Reveille JD. The diffuse infiltrative lymphocytosis syndrome. Clinical and immunogenetic features in 35 patients. AIDS. 1996;10(4):385-391.

5. Itescu S, Winchester R. Diffuse infiltrative lymphocytosis syndrome: a disorder occurring in human immunodeficiency virus- 1 infection that may present as a sicca syndrome. Rheum Dis Clin North Am. 1992;18(3):683-697.

6. Franco-Paredes C, Rebolledo P, Folch E, Hernandez I, del Rio C. Diagnosis of diffuse CD8+ lymphocytosis syndrome in HIV-infected patients. AIDS Read. 2002;12(9):408-413.

7. Pollari FL, Wangsuphachart VL, DiGiacomo RF, Evermann JF. Effects of bovine leukemia virus infection on 
production and reproduction in dairy cattle. Can J Vet Res. 1992;56(4):289-295.

8. Couderc LJ, D'Agay MF, Danon F, Harzic M, Brocheriou C, Clauvel JP. Sicca complex and infection with human immunodeficiency virus. Arch Intern Med. 1987;147(5):898-901.

9. Zafrani L, Coppo P, Dettwiler S, Molinier-Frenkel V, Agbalika F, Guiard-Schmid JB, Pialoux G, et al. Nephropathy associated with the diffuse infiltrative lymphocytosis syndrome. Kidney Int. 2007;72(2):219-224.

10. Agah R, Sockell M, Felsovayni A. Diffuse infiltrative lymphocytosis syndrome in a patient not infected with the human immunodeficiency virus. West J Med. 1996;164(3):266-268.

11. Basu D, Williams FM, Ahn CW, Reveille JD. Changing spectrum of the diffuse infiltrative lymphocytosis syndrome. Arthritis Rheum. 2006;55(3):466-472.

12. Itescu S, Mathur-Wagh U, Skovron ML, Brancato LJ, Marmor M, Zeleniuch-Jacquotte A, Winchester R. HLAB35 is associated with accelerated progression to AIDS. J Acquir Immune Defic Syndr. 1992;5(1):37-45.

13. Yoo J, Baumstein D, Kuppachi S, Singh A, Chander PN. Diffuse infiltrative lymphocytosis syndrome presenting as reversible acute kidney injury associated with Gramnegative bacterial infection in patients with newly diagnosed HIV infection. Am J Kidney Dis. 2011;57(5):752755.

14. Berliner AR, Fine DM, Lucas GM, Rahman MH, Racusen LC, Scheel PJ, Atta MG. Observations on a cohort of $\mathrm{HIV}$-infected patients undergoing native renal biopsy. Am J Nephrol. 2008;28(3):478-486.

15. Ahmed S, Truong L, Eknoyan G, Workeneh B. Evolving spectrum of HIV-associated nephropathy. Nephron Clin Pract. 2012;121(3-4):c131-135.

16. Melica G, Matignon M, Desvaux D, Audard V, Copie-
Bergman C, Lang P, Levy Y, et al. Acute interstitial nephritis with predominant plasmacytic infiltration in patients with HIV-1 infection. Am J Kidney Dis. 2012;59(5):711714.

17. Izzedine H, Brocheriou I, Valantin MA, Camous L, Bourry E, Baumelou A, Deray $G$, et al. A case of acute renal failure associated with diffuse infiltrative lymphocytosis syndrome. Nat Clin Pract Nephrol. 2008;4(2):110-114.

18. Fine DM, Perazella MA, Lucas GM, Atta MG. Kidney biopsy in HIV: beyond HIV-associated nephropathy. Am J Kidney Dis. 2008;51(3):504-514.

19. Benito N, Moreno A, Miro JM, Torres A. Pulmonary infections in HIV-infected patients: an update in the 21st century. Eur Respir J. 2012;39(3):730-745.

20. Saldana MJ, Mones JM. Pulmonary pathology in AIDS: atypical Pneumocystis carinii infection and lymphoid interstitial pneumonia. Thorax. 1994;49(Suppl):S46-55.

21. Miller RF, Isaacson PG, Hall-Craggs M, Lucas S, Gray F, Scaravilli F, An SF. Cerebral CD8+ lymphocytosis in HIV-1 infected patients with immune restoration induced by HAART. Acta Neuropathol. 2004;108(1):17-23.

22. Golbus JR, Gallagher G, Blackburn G, Cinti S. Polyneuropathy associated with the diffuse infiltrative lymphocytosis syndrome. J Int Assoc Physicians AIDS Care (Chic). 2012;11(4):223-226.

23. Moulignier A, Authier FJ, Baudrimont M, Pialoux G, Belec L, Polivka M, Clair B, et al. Peripheral neuropathy in human immunodeficiency virus-infected patients with the diffuse infiltrative lymphocytosis syndrome. Ann Neurol. 1997;41(4):438-445.

24. Meybeck A, Breton G, Aoun N, Adle-Biassette H, Jacobelli S, Vilde JL, Yeni P. Upper respiratory tract involvement in the course of diffuse infiltrative lymphocytosis syndrome in HIV-1-infected patients: report of 2 cases. Clin Infect Dis. 2005;41(2):e22-26. 